\title{
Erratum to: Prevalence of renal impairment among osteoporotic women in the USA, NHANES 2005-2008: is treatment with bisphosphonates an option?
}

\author{
R. Lubwama • A. Nguyen • A. Modi • D. Chirovsky • \\ P. D. Miller \\ Published online: 7 October 2014 \\ (C) International Osteoporosis Foundation and National Osteoporosis Foundation 2014 \\ Erratum to: Osteoporos Int \\ DOI 10.1007/s00198-014-2645-1
}

The name of the fourth author of this article was rendered wrongly in the original publication. The publisher apologizes for the inconvenience caused.

The online version of the original article can be found at http://dx.doi.org/ 10.1007/s00198-014-2645-1.

R. Lubwama $(\bowtie) \cdot$ A. Nguyen

Epidemiology, Merck \& Co Inc, New Jersey, USA

e-mail: robert_Lubwama@merck.com

A. Modi

Global Health Outcomes, Merck \& Co Inc, New Jersey, USA

D. Chirovsky

Health Policy and Management, University of North Carolina,

Chapel Hill, USA

P. D. Miller

Colorado Center for Bone Research, Lakewood, USA 